\title{
Faecal carriage of multi-drug resistant Enterobacteriaceae in hospitalized children at University Teaching Hospital Sylvanus Olympio of Lomé, Togo
}

\author{
${ }^{1}$ Lack, F., ${ }^{1}$ Tsogbalé, A., ${ }^{2}$ Doumegno, J. K., ${ }^{3}$ Dossim, S., ${ }^{1}$ Dagnra, A., and ${ }^{* 1,4}$ Salou, M. \\ ${ }^{1}$ Laboratory of Molecular Biology and Immunology, Faculty of Health Sciences, University of Lomé, Lomé, Togo \\ ${ }^{2}$ Laboratory of Microbiology and Food Quality Control, University of Lomé, Togo \\ ${ }^{3} \mathrm{CHU}$ Kara Medical Biology Laboratory, Kara, Togo \\ ${ }^{4}$ National AMR Reference Laboratory CHU Campus, Lomé, Togo \\ *Correspondence to: mounerous@gmail.com
}

\begin{abstract}
:
Background: High prevalence of infections and associated antibiotherapy may put children at increased risk for development of multidrug-resistance (MDR), mostly to bacterial infections. The objective of this study therefore was to determine the prevalence of gastrointestinal carriage of MDR Enterobacteriaceae among hospitalized children in the Paediatric department of Sylvanus Olympio University Hospital, Lomé, Togo.

Methodology: A descriptive cross-sectional study was carried out on randomly selected hospitalized children in the Paediatric wards of the hospital from November 03 to November 10, 2020, after obtaining informed consent from their parents/guardians. Rectal swabs and stool samples were collected from each participant and cultured for isolation of members of the family Enterobacteriaceae on Hektoen enteric agar containing $4 \mu \mathrm{g} / \mathrm{L}$ cefotaxime, which was incubated aerobically at $37^{\circ} \mathrm{C}$ for 24 hours. The isolates were identified using in-house biochemical tests. Antibiotic susceptibility test (AST) of each isolate to a panel of antibiotics including ertapenem and imipenem was done by the disc diffusion method and interpreted according to the European Committee on Antimicrobial Susceptibility Testing (EUCAST) clinical breakpoints version 2020 V.1.1. ESBL production was detected by the double-disc synergy test of amoxicillin and clavulanic acid, and resistance to carbapenem was inferred by resistance to ertapenem and imipenem discs in the AST. Multi-drug resistance (MDR) was defined as resistance to at least three families of antibiotics. Statistical analysis of data was carried out on Excel 2010 and EPI INFO 7.2 and $p$ value $<0.05$ was considered to be statistical significance. Results: A total of 70 hospitalized children during the study period were randomly recruited with an average age of 4 years 3 days and a range of 1 day to 18 years. The male gender was predominant (54.3\%) with a M: $F$ ratio of 1.2. Samples were culture positive in $85.7 \%(60 / 70)$ and a total of 72 species of Enterobacteriaceae were isolated in $93.3 \%(56 / 60)$ of these cultures. Escherichia coli was the most frequently isolated species $(56.9 \%, 41 / 72)$. More than $90 \%(65 / 72)$ of the isolates were resistant to ampicillin, $58.3 \%(42 / 72)$ to third generation cephalosporins, $59.7 \%(43 / 72)$ to fourth generation cephalosporins, $43 \%$ (31/72) to aminoglycosides, $55.6 \%$ (40/72) were multi-drug resistant, 48.6\% (35/72) were ESBL-producing strains, and $6.9 \%$ (5/72) were carbapenem resistant. Eighty-three percent (29/35) of ESBL-producing and all the carbapenem resistant isolates $(5 / 5)$ were recovered from children on antibiotic therapy. The prevalence of ESBL-producing phenotypes among culture-positive children on antibiotic treatment $(72.5 \%, 29 / 40)$ was significantly higher than among culture-positive children not on antibiotic treatment $(20.0 \%, 4 / 20)$, indicating that antibiotic therapy was significantly associated with carriage of MDR isolates (OR=10.545, 95\% CI $=2.882-38.590$, $p=0.0002$ ).

Conclusion: The high faecal carriage rate of MDR Enterobacteriaceae, which are all ESBL-producing strains, in this study is worrying. There is urgent need to develop measures to monitor and limit the spread of these MDR organisms in children and the community in Togo.
\end{abstract}

Keywords: children; Enterobacteriaceae; multidrug-resistance; faecal carriage; Togo

Received Sept 7, 2021; Revised Dec 21, 2021; Accepted Dec 22, 2021; Published online Jan 18, 2022

Copyright 2022 AJCEM Open Access. This article is licensed and distributed under the terms of the Creative Commons Attrition 4.0 International License $<$ a rel="license" href="http://creativecommons.org/licenses/by/4.0/", which permits unrestricted use, distribution and reproduction in any medium, provided credit is given to the original author(s) and the source. Editor-in-Chief: Prof. S. S. Taiwo 


\title{
Portage d'entérobactéries résistantes aux antibiotiques chez des enfants hospitalisés au CHU Sylvanus Olympio de Lomé, Togo
}

\author{
${ }^{1}$ Lack, F., ${ }^{1}$ Tsogbalé, A., ${ }^{2}$ Doumegno, J. K., ${ }^{3}$ Dossim, S., ${ }^{1}$ Dagnra, A., et ${ }^{* 1,4}$ Salou, M. \\ ${ }^{1}$ Laboratoire de Biologie Moléculaire et d'Immunologie, Faculté des Sciences de la Santé, \\ Université de Lomé, Lomé, Togo \\ ${ }^{2}$ Laboratoire de Microbiologie et Contrôle Qualité Alimentaire, Université de Lomé, Togo \\ ${ }^{3}$ Laboratoire de Biologie Médicale du CHU Kara, Kara, Togo \\ ${ }^{4}$ Laboratoire National de Référence RAM CHU Campus, Lomé, Togo \\ *Correspondance à: mounerous@gmail.com
}

\section{Résumé:}

Contexte: La prévalence élevée des infections associée à une antibiothérapie excessive peuvent exposer les enfants à un risque accru de développer des bactéries multirésistantes (BMR). L'objectif de cette étude était de déterminer la prévalence du portage digestif des entérobactéries mutlirésistantes aux antibiotiques chez les enfants hospitalisés dans le service de pédiatrie du CHU Sylvanus Olympio, Lomé, Togo.

Méthodologie: Une étude transversale descriptive a été réalisée sur des enfants hospitalisés et sélectionnés au hasard dans le service de pédiatrie du CHU Sylvanus Olympio du 03 Novembre au 10 Novembre 2020. Après avoir obtenu le consentement éclairé des parents/tuteurs, des écouvillons rectaux et des échantillons de selles ont été prélevés sur chaque participant et cultivés pour l'isolement des entérobactéries sur la gélose Hektoen contenant $4 \mu \mathrm{g} / \mathrm{L}$ de céfotaxime. Le milieu ensemencé a été incubée en aérobie à $37^{\circ} \mathrm{C}$ pendant 24 heures. Les isolats ont été identifiés à l'aide de tests biochimiques internes. Le test de sensibilité aux antibiotiques (Antibiogramme par la méthode de diffusion sur disque) de chaque isolat à fait appel à un panel d'antibiotiques comprenant l'ertapénème et l'imipénem a été effectué. Les résultats ont interprétés selon les recommandations du Comité Européen sur les Tests de Sensibilité aux Antimicrobiens (EUCAST) version 2020 V.1.1. La production de BLSE a été détectée par le test de synergie à double disque d'amoxicilline et d'acide clavulanique, et la résistance aux carbapénèmes a été déduite par la résistance aux disques d'ertapénème et d'imipénème dans I'AST. La multirésistance aux antibiotiques (BMR) a été définie comme une résistance à au moins trois familles d'antibiotiques. L'analyse des données a été réalisée sur Excel 2010 et EPI INFO 7,2 et la valeur $p<0,05$ a été considérée comme statistiquement significative.

Résultats: Un total de 70 enfants hospitalisés au cours de la période d'étude ont été recrutés au hasard avec un âge moyen de 4 ans 3 jours avec des extrêmes de 1 jour à 18 ans. Le sexe masculin était prédominant $(54,3 \%)$ avec un rapport $M: F$ de 1,2 . Les échantillons étaient positifs en culture dans $85,7 \%(60 / 70)$ et un total de 72 espèces d'entérobactéries ont été isolées dans 93,3\% (56/60) de ces cultures. Escherichia coli était l'espèce la plus fréquemment isolée $(56,9 \%, 41 / 72)$. Plus de $90 \%(65 / 72)$ des isolats étaient résistantsà l'ampicilline, 58,3\% (42/72) aux céphalosporines de troisième génération, 59,7\% (43/72) aux céphalosporines de quatrième génération, $43 \%(31 / 72)$ aux aminosides, 55,6\% (40/72) étaient multirésistants. Par ailleurs, 48,6\% (35/72) étaient des souches productrices de BLSE et 6,9\% (5/72) étaient résistants aux carbapénèmes. Quatre-vingt-trois pour cent (29/35) des isolats producteurs de BLSE et tous les isolats résistants aux carbapénèmes (5/5) ont été isolées chez des enfants sous antibiothérapie. La prévalence des phénotypes BLSE chez les enfants à culture positive sous traitement antibiotique $(72,5 \%, 29 / 40)$ était significativement plus élevée que chez ceux à culture positive ne bénéficiant pas d'une antibiothérapie $(20,0 \%, 4 / 20)$, indiquant que l'antibiothérapie était significativement associé au portage d'isolats de BMR $(\mathrm{OR}=10,545$, IC à $95 \%=2,882-38,590, p=0,0002)$.

Conclusion: Le taux de portage fécal élevé d'entérobactéries BLSE, multirésistantes chez les enfants hospitalisés, dans cette étude est préoccupant. Il est urgent de développer des mesures pour surveiller et limiter la propagation de ces BMR chez les enfants et la communauté au Togo.

Mots-clés: enfants; Entérobactéries; multirésistance; transport fécal; Togo

\section{Introduction:}

Antibiotic resistance is a natural phenomenon but misuse of antimicrobial drugs in humans and animals can accelerate the process (1). Antibiotic resistance is now one of the most serious threats to global health, food security and development. It can affect anyone, at any age and in any country (1). Infections caused by multidrug-resistant (MDR) bacteria are a major public health problem worldwide. According to the 2014 World Health Organization (WHO) published report, the proportion of resistance of
Escherichia coli to third generation cephalosporins (3GC) reached $70 \%$ in the WHO Africa region, $82 \%$ in Europe, and up to $95 \%$ in the South-East Asia, and the proportion of resistance to fluoroquinolones was up to $98 \%$ (2). Resistance to amoxicillin or ampicillin has also remained very high at $100 \%$ of isolated strains $(3,4)$. Resistance rates of various bacterial pathogens progress over time and vary from one country to another $(5,6)$. Data on the intestinal carriage rate of resistant bacteria in children, who are mostly at risk due to frequent infection and antibiotherapy, 
are lacking in Togo. The objective of this study therefore is to determine the faecal carriage rate of MDR Enterobacteriaceae among children in the Paediatric hospital setting at the Sylvanus Olympio University Hospital in Lomé, Togo.

\section{Materials and method:}

\section{Study setting and design}

The study was conducted in the Paediatric Department and the Microbiology Laboratory of the CHU-Sylvanus Olympio (CHU-SO) of Lomé, Togo. It was a descriptive cross-sectional study conducted during the period November 03 to November $10,2020$.

\section{Study participants and sample collection All children hospitalized without any digestive pathologies in the Paediatric dep- artment of the hospital whose parents gave informed consent, were randomly recruited into the study. In newborns, infants and younger children, rectal swabs were used to collected samples, while for older children and adolescents, stool cultures were colle- cted into sterile jar containers. A pre-tested survey form was used to collect demo- graphic (age, gender) and clinical data (dia- gnosis, use of antibiotic, type of antibiotic therapy, duration of hospitalization at time of collection, hospitalization unit etc).}

\section{Microbiological culture isolation \& bacterial identification}

All the rectal and stool samples were immediately seeded on Brain Heart Infusion $(\mathrm{BHI})$ broth and incubated for 5 hours at $37^{\circ} \mathrm{C}$ to improve bacteriological yield (7). After this enrichment phase, $100 \mu \mathrm{L}$ of the broth was transferred to Hektoen enteric agar (Oxoid, UK) supplemented with $4 \mu \mathrm{g} / \mathrm{L}$ cefotaxime and incubated at $37^{\circ} \mathrm{C}$ for 24 hours. Predominant colonies of different morphotypes were identified to species level by using in-house biochemical test panels including triple sugar iron (TSI) agar, sulfur-indole-motility, Simmon citrate agar and urease tests.

\section{Antibiotic susceptibility test (AST)}

Antimicrobial susceptibility test (AST) was performed on each isolate by the agar disc diffusion method according to the European Committee on Antimicrobial Susceptibility Testing (EUCAST) clinical breakpoints version 2020 V.1.1 recommendations. Antibiotic discs used include; penicillins (ampicillin, amoxicillin + clavulanic acid, piperacillin, ticarcillin), cephalosporins (cefalotin, cefoxitin, cefotaxime, ceftazidime, cefepime), carbapenem (imipenem, ertapenem), monobactam (aztreonam), flu- oroquinolones (nalidixic acid, ciprofloxacin, ofloxacin), aminoglycosides (amikacin, gentamicin), phenicol (chloramphenicol), sulfonamide (trimethoprim) and fosfomycin. Staphylococcus aureus ATCC 25923 and Pseudomonas aeruginosa ATCC 27853 were used as control strains.

\section{Detection of ESBL production}

ESBL production was detected by the presence of synergy between the third generation cephalosporins and the inhibitor (clavulanic acid) (8-10). In case of highlevel cephalosporinase production, the combined double-disc synergy test was performed using cloxacillin-supplemented agar medium.

\section{Statistical analysis}

Statistical analysis of data was carried out on Excel 2010 and EPI INFO 7.2 software. Qualitative variables were compared using Chi-square or Fisher's exact test (when an expected value was less than 5) while continuous variables were compared using Students' ' $t$ ' test. A $p$ value $<0.05$ was considered to be statistical significance.

\section{Results:}

Socio-demographic and clinical characteristics of the children

A total of 70 children were included, the average age of the patients was 4 years 3 days with a range of 1 day to 18 years. Infants (age < 1 years) were the most frequently represented age group $(31.4 \%, n=$ 22 ). Male to female ratio was 1.2. Majority of the children were hospitalized in the intensive care units (ICU), with average length of hospitalization of 43 days, and a range of 1 day to 360 days. More than half of the children $(57.1 \%, n=40)$ were on antibiotic therapy, and the most commonly used antibiotic was the combination of cephalosporin and gentamicin 67.5\% $(n=27)$.

\section{Frequency distribution of bacteria isolates:} Out of the 70 samples analyzed, 60 $(85.7 \%)$ cultures were positive and 10 $(14.3 \%)$ were negative. Enterobacteriaceae were isolated in $93.3 \%(56 / 60)$ of the 60 positive cultures, and 72 species of Enterobacteriaceae were isolated with Escherichia coli being the most frequently isolated species $(57.0 \%)$ followed by Klebsiella pneumoniae (26.0\%) (Fig.1).

Antibiotic susceptibility patterns of isolates High resistance rates of all isolated species $(>80 \%)$ were obtained against ampicillin, followed by third generation cephalosporins (58.3\%), while low resistance rate was exhibited to imipenem (Table 1 ). The 
prevalence of multi-drug resistance (MDR) among the Enterobacteriaceae isolates was $55.6 \%$ (40/72), 48.6\% (35/72) were ESBLproducing, and $6.9 \%(5 / 72)$ were resistant to carbapenems.

The frequency distribution of resistance phenotypes of the isolates is shown in Table 2 with the wild type being the most represented in all isolated species. Other resistance phenotypes were also observed with differences in frequency distribution in children on antibiotic therapy from children not on antibiotic therapy (Table 3). ESBLproducing phenotype was the most represented resistance phenotype among the children $(35 / 60,58.3 \%)$ followed by carb- apenem resistant phenotype (6/60, 10.0 $\%)$. The prevalence of ESBL-producing phenotypes among culture-positive children on antibiotic treatment $(72.5 \%, 29 / 40)$ was significantly higher $(\mathrm{OR}=10.545,95 \% \mathrm{CI}=$ 2.882 - 38.590, $p=0.0002$ ) than among culture-positive children not on antibiotic treatment $(20 \%, 4 / 20)$, indicating that antibiotic therapy was significantly associated with carriage of MDR isolates (Table 3).

Factors influencing carriage of MDR strains None of the factors such as gender, age group, or length of hospitalization was significantly associated with the carriage of MDR bacteria (Table 4).

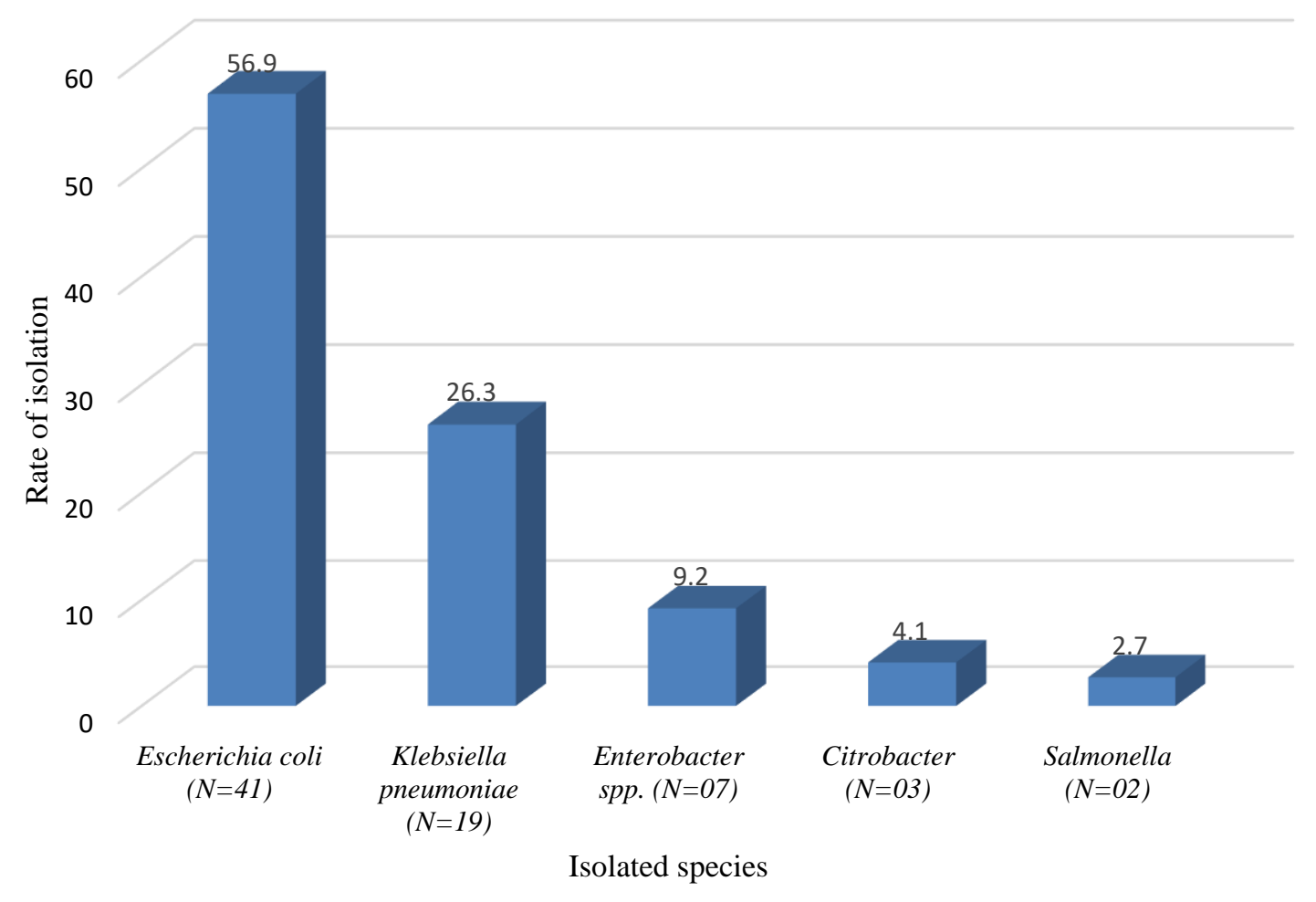

Fig. 1: Frequency of Enterobacteriaceae isolates from hospitalized children 
Table 1: Antibiotic susceptibility patterns of Enterobacteriaceae isolates

\begin{tabular}{|c|c|c|c|c|c|c|}
\hline \multicolumn{2}{|c|}{ Antibiotics } & \multicolumn{5}{|c|}{ Isolated Enterobacteriaceae species } \\
\hline & & $\begin{array}{c}\text { Escherichia coli } \\
n=41(\%)\end{array}$ & $\begin{array}{c}\text { Klebsiella pneumoniae } \\
n=19(\%)\end{array}$ & $\begin{array}{c}\text { Enterobacter } \\
n=7(\%)\end{array}$ & $\begin{array}{c}\text { Citrobacter } \\
n=3(\%)\end{array}$ & $\begin{array}{c}\text { Salmonella spp } \\
n=2(\%)\end{array}$ \\
\hline \multirow[t]{2}{*}{ Ampicillin } & $\mathrm{R}$ & $35(85.4)$ & $18(94.8)$ & $7(100)$ & $3(100)$ & $2(100)$ \\
\hline & $\mathrm{S}$ & $6(14.6)$ & $1(5.3)$ & 0 & 0 & 0 \\
\hline Amoxicillin+ & $\mathrm{R}$ & $8(19.5)$ & $7(36.8)$ & $3(42.9)$ & $1(33.3)$ & $1(50.0)$ \\
\hline clavulanic acid & $\mathrm{S}$ & $33(80.4)$ & $12(63.2)$ & $7(51.1)$ & $2(66.7)$ & $1(50.0)$ \\
\hline Piperacillin+ & $\mathrm{R}$ & $15(36.6)$ & $5(26.4)$ & $4(51.1)$ & 0 & $1(50.0)$ \\
\hline tazobactam & $\mathrm{S}$ & $26(63.4)$ & $14(73.7)$ & $3(42.9)$ & $3(100)$ & $1(50.0)$ \\
\hline \multirow[t]{2}{*}{ Ceftriaxone } & $\mathrm{R}$ & $23(85.4)$ & $11(57.9)$ & $5(71.4)$ & $2(66.7)$ & $1(50.0)$ \\
\hline & $\mathrm{S}$ & $18(14.6)$ & $8(42.2)$ & $2(28.6)$ & $1(33.3)$ & $1(50.0)$ \\
\hline \multirow[t]{2}{*}{ Ceftazidime } & $\mathrm{R}$ & $23(56.0)$ & $11(57.9)$ & $4(51.1)$ & $1(33.3)$ & $1(50.0)$ \\
\hline & $\mathrm{S}$ & $18(43.9)$ & $8(42.2)$ & $3(42.9)$ & $2(66.7)$ & $1(50.0)$ \\
\hline \multirow[t]{2}{*}{ Cefepime } & $\mathrm{R}$ & $23(85.4)$ & $11(57.9)$ & $5(71.4)$ & $2(66.7)$ & $1(50.0)$ \\
\hline & $\mathrm{S}$ & $18(14.6)$ & $8(42.2)$ & $2(28.6)$ & $1(33.3)$ & $1(50.0)$ \\
\hline \multirow[t]{2}{*}{ Cefoxitin } & $\mathrm{R}$ & $10(24.3)$ & $3(15.8)$ & $7(100)$ & $1(33.3)$ & $1(50.0)$ \\
\hline & $\mathrm{S}$ & $31(75.6)$ & $16(84.3)$ & 0 & $2(66.7)$ & $1(50.0)$ \\
\hline \multirow[t]{2}{*}{ Imipenem } & $\mathrm{R}$ & $3(7.3)$ & 0 & $1(14.2)$ & 0 & $1(50.0)$ \\
\hline & $\mathrm{S}$ & $38(92.6)$ & $19(100)$ & $6(85.7)$ & $3(100)$ & $1(50.0)$ \\
\hline \multirow[t]{2}{*}{ Gentamicin } & $\mathrm{R}$ & $15(36.9)$ & $8(42.1)$ & $5(71.4)$ & $2(66.7)$ & $1(50.0)$ \\
\hline & $\mathrm{S}$ & $26(63.4)$ & $11(57.9)$ & $2(28.6)$ & $1(33.3)$ & $1(50.0)$ \\
\hline \multirow[t]{2}{*}{ Ciprofloxacin } & $\mathrm{R}$ & $20(48.8)$ & $10(52.7)$ & $3(42.9)$ & $1(33.3)$ & $1(50.0)$ \\
\hline & $\mathrm{S}$ & $21(51.3)$ & $9(47.4)$ & $4(51.1)$ & $2(66.7)$ & $1(50.0)$ \\
\hline
\end{tabular}

$\mathrm{R}=$ Resistant; $\mathrm{S}=$ Sensitive; $\mathrm{n}=$ number

Table 2: Frequency of resistance phenotypes of Enterobacteriaceae isolates on antimicrobial susceptibility tests

\begin{tabular}{|c|c|c|c|c|c|}
\hline $\begin{array}{l}\text { Resistance } \\
\text { phenotypes }\end{array}$ & $\begin{array}{c}\text { Escherichia coli } \\
n=41(\%)\end{array}$ & $\begin{array}{c}\text { Klebsiella pneumoniae } \\
n=19(\%)\end{array}$ & $\begin{array}{c}\text { Enterobacter } \\
n=7(\%)\end{array}$ & $\begin{array}{c}\text { Citrobacter } \\
n=3(\%)\end{array}$ & $\begin{array}{l}\text { Salmonella spp } \\
\qquad=2(\%)\end{array}$ \\
\hline Wild type & $7(17.1)$ & $7(36.9)$ & $1(14.3)$ & $1(33.3)$ & 0 \\
\hline ESBL+ Carbapenems & $1(2.4)$ & 0 & $2(28.5)$ & 0 & $1(50.0)$ \\
\hline ESBL+ Quinolone & $10(24.4)$ & $7(36.9)$ & $1(14.3)$ & 0 & 0 \\
\hline ESBL (Synergic picture) & $5(12.2)$ & 0 & $1(14.3)$ & 0 & 0 \\
\hline ESBL+ Aminoglycosides & $2(4.9)$ & $3(15.7)$ & $1(14.3)$ & $1(33.3)$ & 0 \\
\hline Carbapenems & $1(2.4)$ & 0 & 0 & 0 & 0 \\
\hline Aminoglycosides & $2(4.9)$ & 0 & 0 & 0 & 0 \\
\hline Quinolone & $2(4.9)$ & 0 & 0 & $1(33.3)$ & 0 \\
\hline $\begin{array}{c}\text { Other resistance to } \\
\text { beta lactams }\end{array}$ & $11(26.8)$ & $2(10.5)$ & $1(14.3)$ & 0 & $1(50.0)$ \\
\hline
\end{tabular}


Table 3: Distribution of resistance phenotype of Enterobacteriaceae isolates in culture-positive children with respect to antibiotic treatment

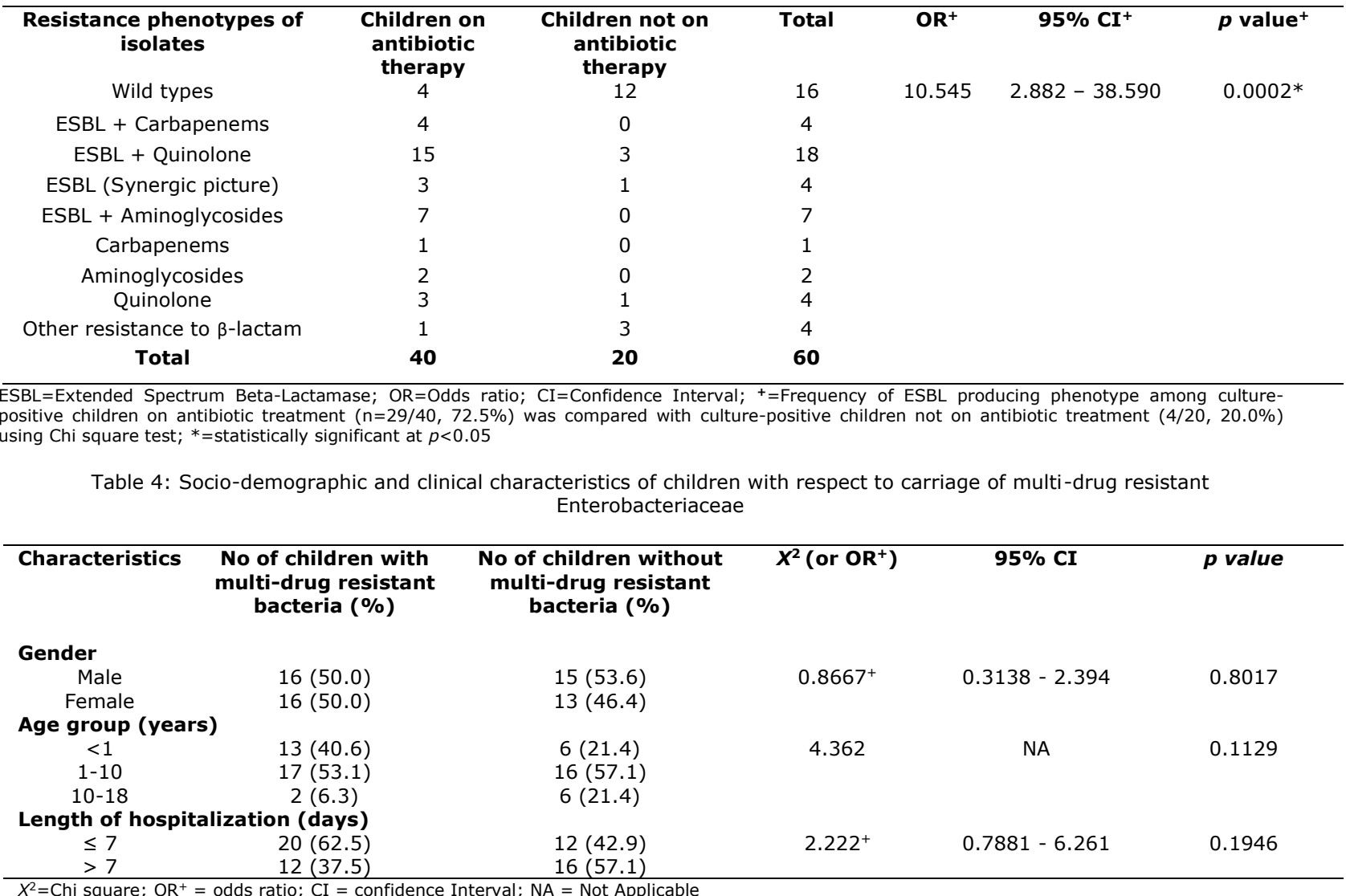

\section{Discussion:}

Clinically significant levels of resistance to various antibiotic classes have developed in most Gram-negative bacteria, although, there is marked geographic variation in the prevalence of resistance. Historically, many forms of antibiotic resistant organisms emerged in and were disseminated from healthcare facilities in high-income settings, but in more recent times, hospitals in low and middle-income countries (LMICs) appear to have been the origin and amplifiers of several forms of resistance. Many factors such as weak antibiotic stewardship, limited infection control resources, and overuse of antibiotics promote the emergence and spread of antibiotic resistant organisms in hospitals, especially where there are no microbiological diagnostic services for the identification of resistance. Due to high antibiotic therapy requirement in children as a result of frequent childhood infections, they are at high risk for emergence and reservoir of multidrug resistance. This is one of the reasons for determining the prevalence of gastrointestinal carriage of multi-drug resistant Enterobacteriaceae (MDR-E) among hospitalized children in the Paediatric department of Sylvanus Olympio University Hospital in Lomé, Togo.

The average age of children in our study population was 4 years 3 days, infants were the most represented $(31.4 \%)$, and the male gender was predominant, with a male to female ratio of 1.2. Our findings are comparable to those reported by Pessinaba et al., (7) in Togo in their study of 81 children under 5 years of age, of which $64(79.0 \%)$ were infants, and male to female ratio was 1.4, which is close to the figure reported in our study. The average length of hospitalization in our study was 43 days with a range of 1 day to 360 days. A study in Switzerland reported an average length of hospitalization of 25.5 days (8). The longer hospitalization observed in our study could be explained by the inclusion of children hospitalized in the oncology unit, with long-term hospitalization. During hospitalization, $60.0 \% \quad(n=42 / 70)$ of children were on antibiotic therapy. In the Switzerland study (8), higher number of children $(86.9 \%)$ were on antibiotic therapy. In another similar study conducted in France (9), $40.5 \%$ of the children were on antibiotic treatment and in $41.2 \%$ of cases, the antibiotic was a third-generation cephalosporin (3GC). Our study found similar percentage of 3GC use.

In our study, $E$. coli was the most frequently isolated bacteria $(57 \%, \mathrm{n}=41 / 72)$ followed by $K$. pneumoniae $(26 \%, n=19 / 72)$. This agrees with the findings of previous 
studies conducted in Togo from 2015 to 2016 on intestinal carriage of ESBL Enterobacteriaceae (10), where $E$. coli was the most frequently isolated strain, and another study conducted from 2010 to 2019 on the prevalence of MDR Enterobacteriaceae (10), which reported $E$. coli $(64.6 \%)$ as the most frequently isolated strain, followed by $K$. pneumoniae $(22.25 \%)$. Our findings are also comparable to other studies in Burkina Faso (11), Mali (12) and France (9) reporting $E$. coli as the most frequently isolated strain followed by $K$. pneumoniae. In contrast to our study, the studies conducted in GuineaBissau (13) and Switzerland (8), had predominance of $K$. pneumoniae, followed by E. coli.

More than $90 \%(n=65)$ of the bacterial isolates in our study were ampicillin resistant, which agrees with the report of a similar study in Chad in 2017 (14), which reported $96 \%$ resistance to amoxicillin. Fifty-eightpoint three percent $(n=42)$ of the isolates were resistant to $3 G C s$ and $59.7 \%(n=43)$ to fourth-generation cephalosporins (4GCs). The study by Sadji et al., (10) reported 38.9\% resistance to 3GCs in children 0-15 years of age, and Pessinaba et al., (7) reported resistance to $3 G C s$ by all the isolates and all $K$. pneumoniae isolates were resistant to 4GCs in their study. Isendahl et al., (13) in GuineaBissau reported resistance rate to 3GCs of over $94 \%$ for $E$. coli and over $97 \%$ for $K$. pneumoniae.

Resistance of $43 \%$ of the Enterobacteriaceae isolates to aminoglycosides was reported in our study with $K$. pneumoniae $(42.1 \%)$ and $E$. coli $(36.5 \%)$. Resistance to quinolones was higher than aminoglycoside, with $52.6 \%$ for $K$. pneumoniae and $48.7 \%$ for E. coli. In a similar study in Togo, $80 \%$ and $94 \%$ of isolates recovered from cultures were resistant to quinolones and aminoglycosides respectively (10). A study in Mali (12) reported resistance of $36-70 \%$ to aminoglycosides and $20-50 \%$ to quinolones. In the GuineaBissau study (13), E. coli isolates were more resistant to quinolones ( $81 \%$ ) than to aminoglycosides $(43.7 \%)$. The results of these studies are similar to ours. More than $90 \%$ of the isolates in our study were resistant to cotrimoxazole. In 2017, resistance of about $80 \%$ to co-trimoxazole was reported in Chad (14). This observation could be explained by the increase in the prevalence of resistance over time. Fortunately, all of our isolates were sensitive to colistin, which is a cheering news in combating antibiotic resistance in our communities, although colistin is a relatively toxic antibiotic that is only used as one of the antibiotics of "last resort" for the treatment of serious Gram-negative bacterial infections, where other antibiotics have failed.
The prevalence of MDR Enterobacteriaceae (MDR-E) in our study was $55.6 \%(n=$ $40 / 72), 48.6 \%(n=35 / 72)$ were ESBL-producing strains, and $6.9 \%(n=5 / 72)$ were carbapenem resistant strains. A study in Togo covering the period 2010-2019 reported a MDR prevalence rate of $34.8 \%$ (10). The high prevalence of faecal carriage of MDR-E isolates among the children in our study is worrying, because carriage of these pathogens is a risk factor for subsequent infections with MDR pathogens.

The most frequent resistance mechanism was ESBL production in $48.6 \%$ of our isolates. In Togo, many studies conducted in the general population have reported ESBL-E prevalence rates of $22.4 \%$ in 2011 (15), and $60.4 \%$ in 2015-2016 among children (10). These results lead us to conclude that ESBLproducing strains are expanding in our populations. In other African countries, studies conducted in Burkina Faso (11), Mali (12), Guinea-Bissau (13), Chad (14) and Senegal $(15,16)$ reported ESBL prevalence rates ranging between $32 \%$ and $34 \%$. In Burkina Faso, Ouédraogo et al., (11) reported 24\% ESBL carriage rate among children in Paediatrics setting. In Europe, a study carried out in France reported a prevalence rate of $6.7 \%$ in 2012 (9), which increased sharply, with a carriage rate of $10.2 \%$ among community children in 2015 in another French study (17). However, the difference between the prevalence rates in studies from Europe and those from Africa shows that ESBL-producing strains are more widespread in the African populations.

In our study, $85.7 \%(30 / 35)$ of the ESBL-producing strains were isolated from patients on antibiotic therapy. The study conducted in 2012 on children in nursery (9), and many other studies (10-18) had reported that children who were on antibiotic treatment or had received antibiotic treatment less than 3 months previously, were those who carried strains resistant to 3GCs or strains that produced ESBLs. In fact, in our study, statistical analysis showed a significantly higher carriage rate in culture-positive children on antibiotic treatment, who were more than 10 times likely to carry ESBLproducing strains, than culture-positive children not on antibiotic treatment $(O R=10.545$, $95 \% \mathrm{CI}=2.882-38.590, p=0.0002)$.

There was no significant association between carriage of MDR-E and factors such as gender, age group and length of hospitalization in our study. None of the previously cited studies reported association between gender and age of patients, with carriage of MDR-E, and these agree with the findings of our study. Contrary to our study however, Sadji (10) reported age as a factor influencing 
the carriage of MDR-E, in which subjects aged 45 years and above were 1.7 times more likely to carry MDR-E in their study.

\section{Conclusion:}

The results of our study showed a worrying high level of faecal carriage of MDR$\mathrm{E}$, which were all ESBL-producing strains, in the children population. Antibiotic treatment was the only factor significantly associated with carriage of MDR-E in the study. There is urgent need to develop measures to monitor and limit the spread of these MDR organisms in children and the community in Togo.

\section{References:}

1. World Health Organization. Antibiotic resistance https://www.who.int/fr/news-room/factsheets/detail/antibiotic-resistance.

Accessed 17 Nov 2019.

2. Dantas, A. Antimicrobial resistance: Global report on surveillance, 2014. WHO. 2014: 256 https://www.academia.edu/37107059/Antimicro bial resistance oms abril?email work card=vie w-paper. Accessed 17 Nov 2020.

3. Ebongue, C. O., Tsiazok, M. D., Mefo'o, J. P. N., Ngaba, G. P., Beyiha, G., and Adiogo, D. Evolution of antibiotic resistance of enterobacteria isolated at the Douala General Hospital from 2005 to 2012. Pan Afr Med J. 2015: 20. https://www.ncbi.nlm.nih.gov/pmc/articles/PMC 4482524/

4. El Bouamri, M. C., Arsalane, L., Kamouni, Y., et al. Current antibiotic resistance profile of uropathogenic Escherichia coli strains and therapeutic consequences. Prog Urol. 2014; 24: 1058-1062

5. Spares, M., Arnaud, I., Simon, S. L., et al. Multidrug-resistant bacteria in healthcare establishments in 2018. 2018 data from the BMR - Raisin Saint - Maurice network: Sante publique France, 2019. https://www.sante publiquefrance.fr/. Accessed 9 February 2020.

6. Belmonte, O. Drouet, D. Alba, J., et al. Evolution of the resistance of Enterobacteriaceae to antibiotics on Reunion Island: emergence of extended spectrum beta-lactamases. Pathol Biol. 2010; 58: 18-24. http://www.sciencedirect. com/science/article/pii/S0369811409001588

7. Pessinaba, C. N., Landoh, D. E., Dossim, S., and Bidjada, B. Screening for digestive carriage of extended-spectrum beta-lactamase-producing enterobacteria in children under 5 in Lomé, Togo. Médecine et Infect Dis. 2018; 48: 551-
554

Mirabaud, I. Extended-spectrum beta-lactamamase enterobacteriaceae in Paediatrics Thesis n Med. 10303, University of Geneva 9. Pascale, B. B., and Dunais, V. B. Digestive carriage of enterobacteriaceae resistant to 3rd generation cephalosporins and producers of extended spectrum beta-lactamase (ESBL) in children attending collective crèches in the Alpes-Maritimes in 2012 BEH 24-25 September 9, 2014

10. Sadji, A. Prevalence of Enterobacteriaceae multiresistant to antibiotics and factors associated with multi-resistance, National Institute of Hygiene, Togo, January 2010 to December 2019. Master thesis in Intervention Epidemiology University Joseph KI - Zerbo.

11. Ouedraogo, A., Sanou, S., Kissou, A., et al. Fecal carriage of extended spectrum beta lactamase-secreting enterobacteria in hospitalized patients and healthy volunteers in Burkina Faso. Microb Drug Resist. 2017; 23 (1) :63-70. doi: $10.1089 / \mathrm{mdr} .2015 .0356$

12. Tandé, D., Jallot, N., Bougoudogo, F., Montagnon, T., Gouriou, S., and Sizun, J. Extended-Spectrum $\beta$-Lactamase - Producing Enterobacteriaceae in Malian Orphanage. Emerg Infect Dis. 2009; $15 \quad$ (3): 472-474. doi: $10.3201 /$ eid1503.071637

13. Isendahl, J., Turlej-Rogacka, A., Manjuba, C., Rodrigues, A., Giske, C. G., and Naucle, P. Fecal Carriage of ESBL-Producing $E$. coli and $K$. pneumoniae in Children in Guinea-Bissau: A Hospital-Based Cross-Sectional Study. PLoS One 2012; 7 (12): e51981

14. Linefiene, L., Tankoano, A., Fissou Yandai, H., and Somda, N. S. Prevalence and antibiotic susceptibility of diarrheal strains of Escherichia coli in children under five in Chad. Rev Microbiol Ind San Environ. 2017; 11 (1): 16-30

15. Durand, A., Dupré, C., and Robriquet, L. Faut-il isoler les patients porteurs de BMR? Réanimation. 2016 ; 25 : 318-327. https://doi.org/10.1007/s13546-016-1184-5

16. Ruppe, E., Woerther, P., Diop, A., et al. Carriage of CTX-M-15-Producing Escherichia coli Isolates among Children Living in a Remote Village in Senegal. Antimicrob Agents Chemother. 2009; 53 (7): 3135-3137

17. Basmaci, R., and Cohen, R. What should a Paediatrician know about extended spectrum beta-lactamase-producing Escherichia coli? Perfectionnement en Pédiatrie. 2018; 1 (1): 6267. https://www.sciencedirect.com/science/article/pi i/S2588932X18300093

18. Rodriguez-Villalobos, $\mathrm{H}$., and Struelens, M. J. Bacterial resistance by extended spectrum $\beta$ lactamases: implications for the resuscitator Extended spectrum $\beta$-lactamases mediated bacterial resistance: Implications for the intensivist focus. Resuscitation. 2006; 15: 205213 